ARTICLE

https://doi.org/10.1057/s41599-020-0476-6

\title{
The influence of occupation on the longevity of Japanese traditional artists
}

\author{
Naoyuki Hayashi (i) ${ }^{1,2 \bowtie}$ \& Kazuhiro Kezuka $a^{1,2}$
}

\begin{abstract}
The long-term lifestyle is known to affect lifespan and mortality. In particular, it is well known that exercise habit decreases the mortality. The effects of performing strenuous exercise, however, as an occupation over a lifetime have been unclear. Here we show the effects of various occupations that include being sedentary and performing music and exercise activities and/or birth year on longevity of 699 professional male artists either alive or dead, as reported in books and webpages. Kaplan-Meier analysis showed a significant effect of occupation type on longevity among the four Japanese traditional arts professions of Kabuki, Sado, Rakugo and Nagauta, which include strenuous exercise, and tea ceremonies, telling comic stories and playing instruments while sitting, respectively. Discrete-time logistic regression analysis showed that the lifespan was significantly shorter for Kabuki actors than among the other three Japanese traditional artists. This result suggests that daily strenuous exercise as an occupation shortens rather than prolongs the lifespan.
\end{abstract}

\footnotetext{
${ }^{1}$ Institute for Liberal Arts, Tokyo Institute of Technology, Ookayama 2-12-1-W9-1, Meguro 152-8552, Japan. ${ }^{2}$ Department of Social and Human Sciences, Tokyo Institute of Technology, Ookayama 2-12-1-W9-1, Meguro 152-8552, Japan. ${ }^{凶}$ email: naohayashi@ila.titech.ac.jp
} 


\section{Introduction}

ongevity is a concern for many people. Stories about immortality have existed in various regions worldwide since ancient times. Famous examples include the depiction of Gilgamesh as being afraid of his own death and hoping to find immortality in Mesopotamia civilization, and that of the First Emperor of Qin seeking immortality in the Shiji, which is a monumental history of ancient China. Nowadays both industry and academia are vigorously exploring substances for countering aging and age-associated diseases (e.g., Bakula et al., 2018).

It is well known that lifespan and mortality are affected by lifestyle habits, with especially the positive effects of exercise having been demonstrated in experimental science fields. Strong evidence has accumulated from long-term prospective follow-up studies of the risk of death from many diseases associated with exercise habits since the seminal study of Morris et al. comparing the mortality rate between the drivers and conductors of buses (Morris et al., 1953). A follow-up survey targeting about 10,000 university graduates (the Harvard Alumni Health Study) found a low mortality rate among those performing vigorous intensity exercise (Sesso et al., 2000; Lee and Paffenbarger, 2000). A study of the physical fitness level and mortality rate in an American population with a mean follow-up period of more than 8 years showed that the all-cause mortality rate is low due to lower rates of cardiovascular diseases and cancer in subjects with a high level of physical fitness (Blair et al., 1989). Physical activity has been found to be associated with lower risks of mortality and cardiovascular disease events in individuals from low-income, middleincome and high-income countries, implying that increasing physical activity is an effective strategy for reducing deaths in middle age (Lear et al., 2017). The importance of regular exercise to mitigating the increasing morbidity and mortality rates associated with obesity-related diseases in developing countries has also been pointed out (Misra and Khurana, 2008), and the effectiveness of exercise and dietary interventions has been demonstrated (Müller et al., 2016). Strong evidence supporting exercise habits on longevity has piled up. This has prompted researchers and policy-makers to focus on the health benefits of regular exercise.

The influence of having a lifetime occupation on the lifespan that involves performing strenuous exercises on mortality remains unknown despite exercise being well known to extend the lifespan. For example, the lifespans of dancers and construction workers who daily engage in strenuous exercise have not been examined, and the mortality rate was recently reported to be higher for manual labour than for non-manual labour in various European countries (Tanaka et al., 2019). However, the data in that study were collected during 1990-2015, the cohort was not fully characterized, and the exercise intensity in the manual-labour group was not clear. Many types of manual labour do not include vigorous exercise, particularly in developed countries, and so the effects of performing daily vigorous exercise as an occupation over a lifetime on mortality are still unclear.

The effect of lifetime occupation on the lifespan can be examined by analysing social statistics (Tanaka et al., 2019). There are adequate data samples from Japan that could be utilized to reveal the effect of daily vigorous exercise over a lifetime on mortality. The Japanese traditional arts professions of Kabuki, Sado, Rakugo and Nagauta include strenuous exercise, tea ceremonies, telling comic stories and playing instruments while sitting, respectively. Using the data on lifespan for these professions, we performed comparisons while adjusting for lifestyle, sex, residence location and diet. These occupations are associated with a stable living situation and earning sufficient wages and reputation. Most of these workers were males. The practitioners in a given era live in big cities (mainly in Tokyo and Osaka) and consume similar diets in an island country. The number of people who enjoyed the performances in these professions increased during the middle of the Edo period (1603-1867) as the financial status of the townspeople increased. There are records available on the birth and death dates of successful artists engaging in these occupations since $1700 \mathrm{AD}$. Thus we can collect the data and make a cohort dataset, thus making them comparable in many aspects other than their occupations.

There are substantial differences among these professions, whereas other factors are similar, as stated above. Kabuki actors sing and dance, which often includes intense movements, and a survey found that $88 \%$ of 216 Kabuki performers reported having at least one performance-related medical problem, with back, knee and foot injuries being the most common (Brodsky, 2001). In Sado, tea masters produce and host a ceremony of serving and consuming Japanese tea while they are sitting, and thus they seldom exercise during their work. Rakugo is a type of comedy story-telling performed alone while a performer sits, and each story lasts for from about $15 \mathrm{~min}$ to $1 \mathrm{~h}$. Nagauta involves music accompanied by a three-stringed Japanese banjo while the performer sits, in which the performance basically consists of multiple songs and playing the banjo for about $15 \mathrm{~min}$ to $1 \mathrm{~h}$.

To examine the effect of daily vigorous exercise as an occupation, we compared longevity in practitioners of the four Japanese traditional arts of Kabuki, Sado, Rakugo and Nagauta, with Kabuki actors constituting a vigorous exercising group. We included the lifespan of Noh actors (whose occupation also includes exercise) as preliminary data because of the difficulty of obtaining the name and lifespan of the actors from a sufficient number of reliable literature sources. To allow comparisons with those who consumed the best diets and received the best medical treatment at that time, Shogun data (on family members of generals) and Emperor data (on members of the Imperial Family) were added. We hypothesized that Kabuki and Noh actors showed longer lifespans since they regularly engage in exercise as their daily work; that is, exercise habits formed an integral part of their profession for a long time. Mostly males are involved in the above occupations, and so we only collected data on males.

\section{Methods}

We collected the birth date or both the birth and death dates of males in a personal-names dictionary and official webpage for arts events, and for the Imperial Family (Emperor family members) and families positioned to accede to the shogunate (Shogun family members) among those who were born after $1700 \mathrm{AD}$ (Hayashi and Kezuka, 2020). We applied the following two exclusion criteria: (1) fewer than two data sources confirming both the date of birth and death, and (2) death due to battle, suicide, or accident, or dying at younger than 20 years. We used data on those who lived to an age of at least 20 years since infant deaths would have substantially affected the data analyses. For Noh actors, we accepted data confirmed by only one source for both the birth and death dates, since far less data are available for Noh actors than for the other occupations. Data were confirmed on 1 July 2018. To eliminate arbitrariness of data selection, three research assistants who did not know the study hypothesis collected the data, with the two authors not being involved.

One of the three research assistant counted the number of performances per year in 1970, 1990 and 2010 among 36 Kabuki actors selected randomly from the official webpage of the Japan Actors' Association. The performance solely covered 1 month, which is normal for a Kabuki performance.

Kaplan-Meier analysis and discrete-time logistic regression analysis were used to examine the effect of occupation on 
longevity. We controlled the effect of era of living by including the birth year in three ways, with model 0 acting as a base model that included only age (baseline hazard) and occupations, and with Shogun and Emperor as reference categories. In models 1, 2 and 3 we controlled the birth year of samples: model 1 had a born-in-20th-century dummy variable, model 2 had the birth year as a continuous variable and model 3 added the square of the birth year to model 2 .

\section{Results}

We collected data on 699 professional male artists, which included 546 who had already died. The ranges of the number of performances of randomly selected 36 Kabuki actors in 1970, 1990 and 2010 were 6-24, 5-17 and 9-27, respectively.

Kaplan-Meier analysis (Fig. 1) showed that the survival functions could be divided into two distinct groups: (1) Shogun and Emperor family members and (2) others. Descriptive statistics using the Kaplan-Meier method showed Shogun and Emperor family members to have shorter lifespans (Table 1). A generalized Wilcoxon test confirmed a significant effect of occupation, with a difference between categories in the survival function (chi square $=109.0, p<0.05$, d.f. $=6$ ).

Discrete-time logistic regression analysis showed significant shorter longevity in Kabuki actors among other occupation (Table 2). After controlling the effect of birth year, which is a proxy for the social, sanitary and medical environment, there was no effect of Kabuki; this means that being a Kabuki actor has no effect on lifespan once the birth year is controlled.

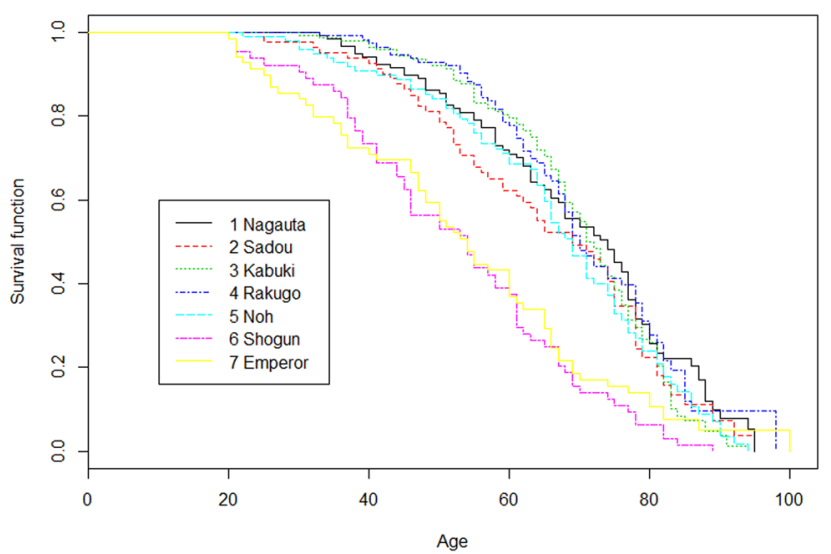

Fig. 1 Survival function. The Shogun and Emperor family members showed clearly lower survival compared to the rest of the study population.

\begin{tabular}{|c|c|c|c|c|c|}
\hline & \multicolumn{3}{|c|}{ Lifespan } & \multirow[t]{3}{*}{ Sample size } & \multirow{3}{*}{$\begin{array}{l}\text { No. of } \\
\text { events } \\
\text { (deaths) }\end{array}$} \\
\hline & $95 \%$ & & $95 \%$ & & \\
\hline & Lower & Median & Upper & & \\
\hline \multicolumn{6}{|c|}{ Occupation } \\
\hline Kabuki & 69 & 71 & 75 & 150 & 120 \\
\hline Nagauta & 68 & 74 & 77 & 119 & 89 \\
\hline Rakugo & 68 & 70 & 78 & 115 & 75 \\
\hline Sado & 62 & 69 & 75 & 82 & 59 \\
\hline Noh & 66 & 69 & 74 & 100 & 75 \\
\hline Shogun & 46 & 54 & 61 & 64 & 64 \\
\hline Emperor & 48 & 54 & 61 & 69 & 64 \\
\hline
\end{tabular}

Shogun and Emperor family members have significantly shorter lifespans than other occupation groups.

\section{Discussion}

Contrary to the hypothesis, the lifespan of Kabuki and Noh actors (whose occupations include dancing) is not longer than those of the other analysed professions. The lifespan of Kabuki actors was shorter than or similar to those who engage in the other occupations, except for the Emperor and Shogun family members. Also, Noh actors have a similar lifespan to Sado performers, Nagauta performers and Rakugo story-tellers, whose occupations are relatively sedentary and do not include exercise. The number of performances in Kabuki actors ranged from 5 to 27 titles annually, meaning that they each performed in different titles at least once every 2 months. This count includes solely performances over a single month, and one performance took roughly $1 \mathrm{~h}$. Besides the 1-month performances, the actors had been participating in daily lessons and short-term performances lasting from 1 to 3 days. These findings confirm Kabuki actors as being appropriate subjects for inclusion in a daily strenuous exercise group, and reveal that performing daily vigorous exercise as part of a profession does not prolong the lifespan. A particularly surprising result was that the Emperor and Shogun family members had shorter lifespans despite being assumed to have received the best medical care and food.

The hypothesis that the lifespan is prolonged in people engaged in occupations that include regular strenuous exercise was rejected, whereas there is strong evidence supporting that exercise habits prolong the lifespan (Blair et al., 1989; Sesso et al., 2000; Lee and Paffenbarger, 2000; Lear et al., 2017). We used Kabuki and Noh actors as the occupations involving regular exercise. Kabuki actors showed a shorter lifespan than the other occupations except for Emperor and Shogun family members. In the discrete-time logistic regression analysis controlling the birth year, the coefficient for Noh was larger than that for Sado and Rakugo. A negative coefficient means a longer lifespan than the reference category (i.e. Emperor and Shogun family members), and a lower coefficient means a longer lifespan; thus, the hypothesis was rejected.

We can propose three factors that could shorten the lifespan and/or support the overwhelming favourable effect of daily exercise on longevity: types of exercise, lead-containing white powder, and genes carried by Kabuki and Noh actors. First, excessive exercise by Kabuki and Noh actors could overwhelm a favourable effect of daily exercise on longevity, since there is evidence that excessive work does not exert advantageous effects on the risk of diseases. No beneficial effects were found for frequent physical activity on vascular disease risk in 1.1 million females (Armstrong et al., 2015), in contrast to the beneficial effects of moderate exercise. That previous study involved females, which makes its findings difficult to compare with the present study. Nevertheless, it must be noted that the morbidity of coronary heart disease, cerebrovascular disease and venous thromboembolism in females performing strenuous activity daily is similar to that in inactive females. The unique movements during performing Kabuki and Noh involve many slow movements and includes numerous movements that probably act like strength training. Both endurance training and strength training have positive effects on preventing disease and increasing the lifespan. A survey of 80,000 adults suggested that strength training reduces risk of all-causes death by $23 \%$ (Stamatakis et al., 2018), while a survey of 30,000 adults older than 65 years found that performing strength training reduced this risk by $32 \%$ (Kraschnewski et al., 2016). It therefore can be ruled out that the form of dancing influences lifespan.

Second, the lead contained in the white powder used for makeup might be a factor shortening the lifespan in Kabuki actors, who used such powder until it was banned in 1934 in Japan. One of the famous Kabuki actors, Nakamura Fukusuke 4th (later 
Table 2 Results of discrete-time logistic regression analyses.

\begin{tabular}{|c|c|c|c|c|c|c|c|c|}
\hline & \multicolumn{2}{|l|}{ Model 0} & \multicolumn{2}{|l|}{ Model 1} & \multicolumn{2}{|l|}{ Model 2} & \multicolumn{2}{|l|}{ Model 3} \\
\hline Constant & -5.444 & $0.145^{\star \star \star}$ & -5.305 & $0.145^{\star \star \star}$ & 8.523 & $1.307^{\star \star \star}$ & -264.5 & $38.270^{\star \star \star}$ \\
\hline Nagauta & -0.924 & $0.143^{\star \star \star}$ & -0.753 & $0.145^{\star \star \star}$ & -0.598 & $0.148^{\star \star \star}$ & -0.636 & $0.147^{\star \star \star}$ \\
\hline Kabuki & -0.801 & $0.132^{\star \star \star}$ & -0.314 & $0.138^{\star}$ & -0.163 & 0.149 & -0.132 & 0.147 \\
\hline Sado & -0.734 & $0.162^{\star \star \star}$ & -0.636 & $0.163^{\star \star \star}$ & -0.569 & $0.164^{\star \star \star}$ & -0.589 & $0.164^{\star \star \star}$ \\
\hline \multicolumn{9}{|c|}{ Age (ref. 30s and under) } \\
\hline $40 s$ & 1.516 & $0.183^{\star \star \star}$ & 1.531 & $0.183^{\star \star \star}$ & 1.541 & $0.183^{\star \star \star}$ & 1.531 & $0.183^{\star \star \star}$ \\
\hline $50 \mathrm{~s}$ & 2.198 & $0.165^{\star \star \star}$ & 2.221 & $0.165^{\star \star \star}$ & 2.240 & $0.165^{\star \star \star}$ & 2.223 & $0.165^{\star \star \star}$ \\
\hline $60 \mathrm{~s}$ & 2.897 & $0.156^{\star \star \star}$ & 2.949 & $0.156^{\star \star \star}$ & 2.983 & $0.157^{\star \star \star}$ & 2.964 & $0.157^{\star \star \star}$ \\
\hline $70 \mathrm{~s}$ & 3.383 & $0.161^{\star \star \star}$ & 3.496 & $0.162^{\star \star \star}$ & 3.534 & $0.163^{\star \star \star}$ & 3.535 & $0.163^{\star \star \star}$ \\
\hline $80 s$ & 4.164 & $0.180^{\star \star \star}$ & 4.415 & $0.183^{\star \star \star}$ & 4.352 & $0.183^{\star \star \star}$ & 4.434 & $0.185^{\star \star \star}$ \\
\hline AIC & 4930.8 & & 4809.0 & & 4822.8 & & 4767.9 & \\
\hline
\end{tabular}

Nakamura Utaemon 5th, 1866-1940), was known to suffer from lead poisoning (Yoshinaga, 2015). Other occupations that do not use white powder for their occupations include Noh actors, who instead wear masks during their performances. It is possible that lead could affect the prolonging effect of daily exercise on the lifespan. Nevertheless, this explanation cannot fully explain the shorter lifespan after controlling the birth year, which can rule out the usage of harmful white powder.

Third, the effect of heredity could have shortened the lifespan in Kabuki actors. Recent studies have pointed out minor effects of genes on longevity, and thus heredity is not a major factor underlying the short lifespan in Kabuki and Noh actors. There are many marriages between close relatives in the targeted occupations. We can suppose that these actors carry short-lifespan genes that they may have inherited over many years as to shorten the lifespan. Contrary to this supposition, a research study involving data from more than 400 million people revealed that the strongest factor determining lifespan is the lifestyle, but that this impact was $<10 \%$ (Ruby et al., 2018). This means that the short lives of Kabuki actors cannot simply be explained by their genes.

Occupational discrimination, in particular during the Edo period, cannot explain the shorter lifespan in Kabuki actors. Kabuki actors were traditionally discriminated against as citizens during the Edo period (Morita, 1994) despite being popular with the common people. However, this cannot explain the significantly shorter lifespan in Kabuki actors after controlling the birth year in Table 2, since this type of discrimination was banned after 1868.

The effect of high esteem on their performances should be noted in spite of occupational discrimination. The population analysed in the present study is held in high esteem by the general public, which probably contributes to prolonging the lifespan. A relationship between a successful career and lower mortality risk was previously shown in 693 male subjects (Kern et al., 2009). Also, a survey utilizing a database of 4000 composers found that those awarded a benchmark title lived a mean of 9 years longer by than their non-honoured counterparts (Zharinov and Anisimov, 2014). People engaged in social relationships are more likely to live longer (Rizzuto and Fratiglioni, 2014). The population analyed in the present study has high esteem, which in itself tends to extend the lifespan in all professions.

The present results obtained from an analysis of historical data have some implications for the current situation. Recent data have showed that manual work is related to higher rates of cancer, cardiovascular and all-cause mortality in many countries compared to upper and lower class non-manual labour. These rates are similar between manual and upper non-manual labour solely in Japan (Tanaka et al., 2019), which could be due to workplace stressors that are reportedly related to higher mortality (Goh et al., 2015). These previous and the current results suggest that an occupation that involves daily strenuous exercise does not prolong the lifespan. For example, professions related to music and talking showed lifespans comparable to those of Kabuki and Noh. Activities related to music and talking could extend lifespan, but to the best of our knowledge, the direct effects of music and talk on lifespan have not been examined, and so future studies should examine the effects of music and talking on lifespan and mortality rates.

The methodology used in the present study represent a novel way of extracting information from publicly available data, which also allows the study to be reproduced. We collected and analysed publicly available data (Hayashi and Kezuka, 2020), and have released the collected data so that anyone can reproduce the study results. The importance of reproducibility has been pointed out in previous research (Munafò et al., 2017; Peels and Bouter, 2018). Our methodology contributes to the global trend of addressing reproducibility in science.

The presence of selection bias should be carefully considered. We selected data from a personal-names dictionary and official webpage on which only successful people are recorded. Selection bias could be present if the age at which success occurred differed among occupations. Also, Kabuki is a hereditary occupation and so there is a higher probability of becoming famous at a younger age. Thus, even if selection bias was present, this could not explain the shorter lifespan in Kabuki actors. Moreover, this also cannot explain the much shorter lifespan in Emperor and Shogun 
family members, since the name and death data of young members of these families remain in the records.

It cannot be denied that older people are more likely to be included in databases of traditional art workers. This trend is supported by the shorter lifespan in Shogun and Emperor family members, most of whom were chosen as the data set (see Table 1). It is conceivable that food, stressors and sedentary life explain the shortest lifespan of the Shogun and Emperor family members. The diet of the shogun and his family was reportedly not well balanced (Hanley, 1997), though it was thought as the luxurious meal at that time. Moreover, Shogun and Emperor family members are likely to have been exposed to strong stressors and be sitting for long periods. There is also a relationship between workplace stressors and mortality (Goh et al., 2015). A systemic review showed that sedentary behaviour is associated with both all-cause and cardiovascular mortality (de Rezende et al., 2014). Unfavourable daily living habits also adversely influence longevity, which was not known at that time, could therefore have shortened the lifespan of Shogun and Emperor family members.

Limitations. It should be noted that we did not analyse longevity or life expectancy based on precise definition. We used data on subjects who had lived to an age of at least 20 years. While this represents a limitation of the present study, selecting such data is reasonable since infant deaths would have substantially affected the data analyses and were only reported for Shogun and Emperor family members.

We focused on data for males in our analysis, since the professions analysed in this study are often dominated by males due to old-fashioned views about separate jobs in traditional Japanese culture, and thus data for females were lacking. Future studies could investigate whether the trends observed in males are similar to those seen in females, possibly using data obtained from other countries.

Caution is necessary when attempting to draw definitive conclusions regarding the effect of occupation on longevity, considering that the lifespans in the present study were much shorter than average male lifespan in Japan of 81 years in 2016 as reported by WHO. The effects of continuing professional activities other than exercise should also be considered in future research. Furthermore, the effect of retirement should be considered, since retirement is associated with increased body mass in males (Feng et al., 2020) and so it could increase the prevalence of lifestyle-related diseases and thus also mortality.

An effect of country should be noted. The mortality rate in Japan is among the lowest both for manual and non-manual labour across Asian and European countries (Tanaka et al., 2019). In addition, the occupational classes with the highest mortality rates differ between European and Japanese populations. Care is therefore necessary when attempting to generalize the findings of the present study to other countries.

In conclusion, the present findings suggest that daily strenuous exercise as an occupation can shorten rather than prolong the lifespan. The effects of daily strenuous exercise on the analysed artists have been verified, and the results indicate that it may be necessary to determine the optimal amount of exercise for protecting their health. It is also necessary to consider the effects of non-exercise activities in analysed professions, such as playing musical instruments, singing and speaking on health and longevity.

\section{Data availability}

The datasets generated and analysed in the current study are available in the datasets published by Hayashi and Kezuka (2020).
Received: 8 November 2019; Accepted: 23 April 2020;

Published online: 18 May 2020

\section{References}

Armstrong MEG, Green J, Reeves GK, Beral V, Cairns BJ (2015) Frequent physical activity may not reduce vascular disease risk as much as moderate activity: large prospective study of women in the United Kingdom. Circulation 131:721-729

Bakula D, Aliper AM, Mamoshina P, Petr MA, Teklu A, Baur JA, Campisi J, Ewald CY, Georgievskaya A, Gladyshev VN, Kovalchuk O, Lamming DW, Luijsterburg MS, Martín-Montalvo A, Maudsley S, Mkrtchyan GV, Moskalev A, Olshansky SJ, Ozerov IV, Pickett A, Ristow M, Zhavoronkov A, ScheibyeKnudsen M (2018) Aging and drug discovery. Aging 10:3079-3088

Blair SN, Kohl III HW, Paffenbarger Jr RS, Clark DG, Cooper KH, Gibbons LW (1989) Physical fitness and all-cause mortality. A prospective study of healthy men and women. JAMA 262:2395-2401

Brodsky M (2001) Kabuki actors study. Med Probl Perform Art 16:94-98

de Rezende LFM, Lopes MR, Rey-López JP, Matsudo VKR, Luiz OdC (2014) Sedentary behavior and health outcomes: an overview of systematic reviews. PLoS ONE 9:e105620

Feng J, Li Q, Smith JP (2020) Retirement effect on health status and health behaviors in urban China. World Dev 126:104702

Goh J, Pfeffer J, Zenios S (2015) Exposure to harmful workplace practices could account for inequality in life spans across different demographic groups. Health Aff 34:1761-1768

Hayashi N, Kezuka K (2020) Lifespan of Japanese traditional artists. Harvard Dataverse, V1. https://doi.org/10.7910/DVN/S9UUYJ

Hanley SB (1997) Everyday things in premodern Japan: the hidden legacy of material culture. University of California Press, London, UK. p. 8, 134, 159 \& 160

Kern MA, Friedman HS, Martin LR, Reynolds CA, Luong G (2009) Conscientiousness, career success, and longevity: a lifespan analysis. Ann Behav Med 37:154-163

Kraschnewski JL, Sciamanna CN, Poger JM, Rovniak LS, Lehman EB, Cooper AB, Ballentine NH, Ciccolo JT (2016) Is strength training associated with mortality benefits? A 15 year cohort study of US older adults. Prev Med 87:121-127

Lear SA, Hu W, Rangarajan S, Gasevic D, Leong D, Iqbal R, Casanova A, Swaminathan S, Anjana RM, Kumar R, Rosengren A, Wei L, Yang W, Chuangshi W, Huaxing L, Nair S, Diaz R, Swidon H, Gupta R, Mohammadifard N, Lopez-Jaramillo P, Oguz A, Zatonska K, Seron P, Avezum A, Poirier P, Teo K, Yusuf S (2017) The effect of physical activity on mortality and cardiovascular disease in 130,000 people from 17 high-income, middle-income, and low-income countries: the PURE study. Lancet 390:2643-2654

Lee I-M, Paffenbarger Jr RS (2000) Associations of light, moderate, and vigorous intensity physical activity with longevity. The Harvard Alumni Health Study. Am J Epidemiol 151:293-299

Morita Y (1994) Chusei-senmin to Zatsugeinoh no Kenkyu. Yuzankaku, Tokyo, Japan

Morris JN, Heady JA, Raffle PAB, Roberts CG, Parks JW (1953) Coronary heartdisease and physical activity of work. Lancet 262:1053-1057

Misra A, Khurana L (2008) Obesity and the metabolic syndrome in developing countries. J Clin Endocrinol Metab 93:S9-S30

Müller AM, Alley S, Schoeppe S, Vandelanotte C (2016) The effectiveness of e-\& mHealth interventions to promote physical activity and healthy diets in developing countries: a systematic review. Int J Behav Nutr Phys Act 13:109

Munafò MR, Nosek BA, Bishop DVM, Button KS, Chambers CD, du Sert NP, Simonsohn U, Wagenmakers E-J, Ware JJ, Ioannidis JPA (2017) A manifesto for reproducible science. Nat Hum Behav 1:0021

Peels R, Bouter L (2018) The possibility and desirability of replication in the humanities. Palgrave Commun 4:95

Rizzuto D, Fratiglioni L (2014) Lifestyle factors related to mortality and survival: a mini-review. Gerontology 60:327-335

Ruby JG, Wright KM, Rand KA, Kermany A, Noto K, Curtis D, Varner N, Garrigan D, Slinkov D, Dorfman I, Granka JM, Byrnes J, Myres N, Ball C (2018) Estimates of the heritability of human longevity are substantially inflated due to assortative mating. Genetics 210:1109-1124

Sesso HD, Paffenbarger Jr RS, Lee I-M (2000) Physical activity and coronary heart disease in men: the Harvard Alumni Health Study. Circulation 102:975-980

Stamatakis E, Lee I-M, Bennie J, Freeston J, Hamer M, O’Donovan G, Ding D, Bauman A, Mavros Y (2018) Does strength-promoting exercise confer unique health benefits? A pooled analysis of data on 11 population cohorts with all-cause, cancer, and cardiovascular mortality endpoints. Am J Epidemiol 187:1102-1112

Tanaka H, Nusselder WJ, Bopp M, Brønnum-Hansen H, Kalediene R, Lee JS, Leinsalu M, Martikainen P, Menvielle G, Kobayashi Y, Mackenbach JP (2019) Mortality inequalities by occupational class among men in Japan, South 
Korea and eight European countries: a national register-based study, 1990-2015. J Epidemiol Community Health 73:750-758

Yoshinaga $\mathrm{J}(2015)$ Leaded face powder used in 19-20th century in Japan Cosmetology 23:173-176 (in Japanese with English Abstract)

Zharinov GM, Anisimov VN (2014) Music and longevity. Adv Gerontol 4:283-289

\section{Acknowledgements}

The authors thank three research assistants (Mses. Ayako Kaneko, Harumi Kinoshita and Tomoko Muchaku) for collecting the data.

\section{Author contributions}

Both authors contributed to the conception and design of the work, interpretation of the data and revised the draft. NH contributed the acquisition of the data and drafted the work. KK contributed to the analysis of the data.

\section{Competing interests}

The authors declare no competing interests.

\section{Additional information}

Correspondence and requests for materials should be addressed to N.H.
Reprints and permission information is available at http://www.nature.com/reprints

Publisher's note Springer Nature remains neutral with regard to jurisdictional claims in published maps and institutional affiliations.

(c) (i) Open Access This article is licensed under a Creative Commons Attribution 4.0 International License, which permits use, sharing, adaptation, distribution and reproduction in any medium or format, as long as you give appropriate credit to the original author(s) and the source, provide a link to the Creative Commons license, and indicate if changes were made. The images or other third party material in this article are included in the article's Creative Commons license, unless indicated otherwise in a credit line to the material. If material is not included in the article's Creative Commons license and your intended use is not permitted by statutory regulation or exceeds the permitted use, you will need to obtain permission directly from the copyright holder. To view a copy of this license, visit http://creativecommons.org/ licenses/by/4.0/.

(C) The Author(s) 2020 